\title{
Progressive myoclonic epilepsy type 3
}

INSERM

\section{Source}

INSERM. (1999). Orphanet: an online rare disease and orphan drug data base.

Progressive myoclonic epilepsy type 3. ORPHA:263516

A rare, genetic, neuronal ceroid lipofuscinosis disorder characterized by infantile- to early childhood-onset of progressive myoclonic seizures (occasionally accompanied by generalized tonic-clonic seizures) and severe, progressive neurological regression, leading to psychomotor and cognitive decline, cerebellar ataxia, dementia and, frequently, early death. Vision loss may be associated. EEG typically reveals epileptiform activity with predominance in the posterior region and photosensitivity. 